\title{
Uterine NDRG2 expression is increased at implantation sites during early pregnancy in mice, and its down-regulation inhibits decidualization of mouse endometrial stromal cells
}

\author{
Yan Gu', Xuan Zhang ${ }^{2}$, Qian Yang ${ }^{1}$, Jian-mei Wang ${ }^{3}$, Ya-ping He², Zhao-gui Sun ${ }^{2}$, Hui-qin Zhang ${ }^{1}$ \\ and Jian Wang ${ }^{2^{*}}$
}

\begin{abstract}
Background: N-myc down-regulated gene 2 (NDRG2) is a tumor suppressor involved in cell proliferation and differentiation. The aim of this study was to determine the uterine expression pattern of this gene during early pregnancy in mice.

Methods: Uterine NDRG2 mRNA and protein expression levels were determined by RT-PCR and Western blot analyses, respectively, during the peri-implantation period in mice. Immunohistochemical $(\mathrm{IHC})$ analysis was performed to examine the spatial localization of NDRG2 expression in mouse uterine tissues. The in vitro decidualization model of mouse endometrial stromal cells (ESCS) was used to evaluate decidualization of ESCs following NDRG2 knock down by small interfering RNA (siRNA). Statistical significance was analyzed by one-way ANOVA using SPSS 19.0 software.

Results: Uterine NDRG2 gene expression was significantly up-regulated and was predominantly localized to the secondary decidual zone on days 5 and 8 of pregnancy in mice. Its increased expression was associated with artificial decidualization as well as the activation of delayed implantation. Furthermore, uterine NDRG2 expression was induced by estrogen and progesterone treatments. The in vitro decidualization of mouse ESCs was accompanied by up-regulation of NDRG2 expression, and knock down of its expression in these cells by siRNA inhibited the decidualization process.
\end{abstract}

Conclusions: These results suggest that NDRG2 might play an important role in the process of decidualization during early pregnancy.

Keywords: NDRG2, Embryo implantation, Decidualization

\section{Background}

Successful embryo implantation is a critical step in the establishment of pregnancy. Failure of implantation can lead to placental dysfunction, resulting in fetal retardation, preeclampsia (PE), and recurrent miscarriages [1,2]. A series of complex physiological events occur during the exquisitely regulated process of implantation, including blastocyst migration, apposition and adhesion to the luminal epithelium, extensive degradation and remodeling of the

\footnotetext{
*Correspondence: zhangxuancw@outlook.com; wangjiansippr@126.com ${ }^{2}$ NPFPC Key Laboratory of Contraceptive Drugs \& Devices, Shanghai Institute of Planned Parenthood Research, Shanghai, China

Full list of author information is available at the end of the article
}

extracellular matrix, and invasion of trophoblast cells into the maternal endometrium, as well as decidualization of endometrial stromal cells (ESCs) [3, 4]. Decidualization, characterized by proliferation and differentiation of ESCs, is a postovulatory process of endometrial remodeling that occurs in preparation for pregnancy. In addition, during pregnancy, the maternal decidua is essential for the establishment and maintenance of immuno-tolerance at the feto-maternal interface, and it regulates placental function and development of the conceptus [5, 6]. However, the exact molecular mechanism underlying decidualization is still unclear. The identification of the factors involved in 
decidualization would undoubtedly contribute to a better understanding of the implantation process.

$\mathrm{N}$-myc, which belongs to the Myc family, plays an essential role in cell proliferation and differentiation. Although $\mathrm{N}$-myc has been well recognized for its oncogenic biofunction, it has been recently reported to exhibit a dynamic expression pattern during mouse embryonic development [7]. N-Myc downstream-regulated gene 2 (NDRG2), a member of the N-Myc downstream-regulated gene family, encodes a 357-amino acid protein with an apparent molecular weight of $41 \mathrm{kDa}$ [8]. Consistent with its role in cellular differentiation and the stress response, NDRG2 has been identified as a tumor suppressor. Specifically, its expression has been shown to be decreased in a number of different cancer tissues, such as breast [9], liver [10] and gastric cancer tissues [11]. Its expression has also been detected in mouse embryos of various gestational ages. Further, during mouse fetal development, NDRG2 has been found to be strongly expressed in various tissues and organs [12], suggesting its potential role in embryonic development. This gene is phosphorylated by protein kinase $\mathrm{B}$ (PKB/Akt), PKC [13], and glucocorticoid-induced kinase 1 (SGK1) [14]. Akt/PKC signaling is a key regulator of trophoblast function during implantation as well as during early placentation [15]. Thus, we hypothesized that NDRG2 might be involved in the process of embryo implantation, and the present study was undertaken to examine the uterine expression pattern of this gene during the estrous cycle and peri-implantation period in mice.

\section{Methods}

\section{Animals and tissue preparation}

Adult ICR mice aged 8-10 weeks were obtained from the SIPPR/BK Laboratory Animal Company (Shanghai, China) and were caged at a controlled temperature $\left(22^{\circ} \mathrm{C}\right)$ under a $14 \mathrm{~h}$ light: $10 \mathrm{~h}$ dark photoperiod. All experiments were conducted in full compliance with standard laboratory animal care protocols that were approved by the Institutional Animal Care Committee of Shanghai Institute of Planned Parenthood Research (Approval: 2013-19). The estrous cycle was staged by examining vaginal smears as previously described [16], and subsequently the uterine horns were removed from adult females at the diestrus, proestrus, estrous, and metestrus stages $(\mathrm{n}=3$, per stage) immediately after they were sacrificed by cervical dislocation.

To observe the effects of ovarian steroid hormones on uterine NDRG2 expression, adult females were ovariectomized and allowed to rest for 2 weeks. Then, the ovariectomized mice were randomly divided into four groups $(\mathrm{n}=3$, per group) and injected with (1) sesame oil ( $0.1 \mathrm{ml} / \mathrm{mouse})$, (2) $17 \beta$-estradiol $\left(E_{2}, 100 \mathrm{ng} / 25 \mathrm{~g}\right.$ body weight, Sigma, St. Louis, MO), (3) progesterone $\left(\mathrm{P}_{4}, 1 \mathrm{mg} / 25 \mathrm{~g}\right.$ body weight, Sigma), or (4) $E_{2}$ (100 ng/25 g body weight) plus
$\mathrm{P}_{4}$ (1 mg/25 g body weight) according to previously described methods [17-19]. Steroids were dissolved in sesame oil and injected subcutaneously at the same volume $(0.1 \mathrm{ml} /$ mouse $)$. The mice were sacrificed at $24 \mathrm{~h}$ after treatment, and the uterine horns were collected.

Adult female mice were mated with fertile males of the same strain to achieve pregnancy (day $1=$ day of vaginal plug). Pregnancy was confirmed on days 1 and 4 by recovering embryos from the reproductive tracts. Trypan blue dye solution $(0.1 \%$ in saline $(w / v), 0.1 \mathrm{ml}$ per mouse, Sigma) was injected via the tail vein on day 5 to visualize the implantation sites. The entire uterine horn was collected from the pregnant mice on days 1 and 4 of pregnancy $(\mathrm{n}=3$, per day). Uterine tissues at the implantation sites (IS) and non-implantation sites (NI) were separately collected from the pregnant mice on days 5 to 8 of pregnancy ( $\mathrm{n}=3$, per day).

Pseudopregnant mice were obtained by mating adult females with vasectomized adult males. Artificial decidualization was induced by intraluminally infusing $25 \mu \mathrm{l}$ of sesame oil into one uterine horn on day 4 of pseudopregnancy $(n=3)$, and the contralateral un-injected horn served as a control $(n=3)$. The mice were sacrificed at $72 \mathrm{~h}$ after decidualization was artificially induced [20]. Decidualization was confirmed by both weighing the uterine horns and histological examination of the uterine sections.

In the delayed embryo implantation model, pregnant female mice were bilaterally ovariectomized under ether anesthesia at 08:30-09:00 $\mathrm{h}$ on day 4 of pregnancy. The animals in the delayed embryo implantation group and activation group were subcutaneously injected with $\mathrm{P}_{4}(1 \mathrm{mg} /$ 25 g body weight) dissolved in corn oil at 10:00 h from days 4 through 7 of pregnancy to maintain delayed implantation. Then, the animals in the activated implantation group $(\mathrm{n}=3)$ received $\mathrm{E}_{2}(25 \mathrm{ng} / 25 \mathrm{~g}$ body weight) along with $\mathrm{P}_{4}$ to activate embryo implantation [20, 21]. The female mice were euthanized at 10:00 $\mathrm{h}$ on day 8 of pregnancy, and the embryos were verified as previously described [22]. Delayed or activated implantation was confirmed by microscopic observation of the metabolically dormant or activated blastocyst in the uterine flush, as previously described [20]. Progesterone keeps the blastocyst dormant so that the inner cellular mass (ICM) remains underdeveloped. However, when estradiol is supplied with progesterone, the blastocyst becomes active, and the ICM becomes more prominent and distinct in appearance $[20,23,24]$. The uterine tissues were collected and then processed for RNA extraction and immunohistochemistry.

\section{Primary culture of endometrial stromal cells and induction of decidualization in vitro}

The isolation and culture of mouse ESCs was performed following previously described methods with minor modifications [25]. In summary, uterine horns were 
collected from pregnant mice on day 4 and cleaned to remove fat tissues. They were then slit longitudinally and washed thoroughly in Hanks' balanced salt solution (HBSS, Invitrogen, Carlsbad, CA) containing $100 \mathrm{U} / \mathrm{ml}$ penicillin (Invitrogen) and $100 \mu \mathrm{g} / \mathrm{ml}$ streptomycin (Invitrogen). Next, the tissues were placed in HBSS containing $10 \mathrm{mg} / \mathrm{ml}$ trypsin (Sigma), $6 \mathrm{mg} / \mathrm{ml}$ dispase (Invitrogen), $100 \mathrm{U} / \mathrm{ml}$ penicillin and $100 \mu \mathrm{g} / \mathrm{ml}$ streptomycin for $1 \mathrm{~h}$ on ice, followed by incubation for $1 \mathrm{~h}$ at room temperature and $10 \mathrm{~min}$ at $37^{\circ} \mathrm{C}$. Following the digestion steps, the tissues were gently mixed, and the supernatant was discarded to remove the endometrial epithelial clumps. The partially digested tissues were then washed twice in HBSS and placed into HBSS containing $0.15 \mathrm{mg} / \mathrm{ml}$ collagenase (Invitrogen) at $37^{\circ} \mathrm{C}$ for $30 \mathrm{~min}$. Following digestion and shaking, the contents of the tube were passed through a $70 \mu \mathrm{m}$ gauze filter (Millipore, Darmstadt, Germany) to eliminate epithelial sheets. The cell pellets were washed twice and added to Dulbecco's modified Eagle's MediumF12 medium (DMEM/F12) containing $10 \%$ charcoalstripped fetal calf serum (FBS, Invitrogen) and antibiotics at $2 \times 10^{5}$ cells per well in a 6 -well cell culture plate (Invitrogen). After incubation for $1 \mathrm{~h}$, unattached cells were removed by several washes with HBSS, and cell culturing was continued after the addition of fresh DMEM/ F12 containing $1 \%$ charcoal-stripped FBS, $100 \mathrm{U} / \mathrm{ml}$ penicillin, $100 \mu \mathrm{g} / \mathrm{ml}$ streptomycin, $10 \mathrm{nM} \mathrm{E}_{2}$, and $1 \mu \mathrm{M} \mathrm{P}_{4}$ to induce decidualization of the ESCs.

\section{siRNA transfection}

NDRG2-targeting siRNAs were purchased from Santa Cruz Biotechnology, Inc. (NDRG2 siRNA (m) sc-40758, and sc-3700 7was used as the irrelevant control siRNA, Santa Cruz, Santa Cruz, CA). Prior to the in vitro decidualization of ESCs, NDRG2 siRNAs and control siRNAs were transfected into cultured ESCs according to the siPORT $^{\mathrm{mm}} \mathrm{NeoFX}^{\mathrm{sm}}$ protocol (Ambion/Life Technologies, Grand Island, NY). Briefly, $4 \mu \mathrm{l}$ of siPORT NeoFX transfection reagent was mixed with $100 \mathrm{nM}$ of siRNA duplexes to form complexes, and this mixture was then dispersed into each well of a 6-well cell culture plate.

\section{Immunohistochemistry and histological analyses}

Uterine tissues were fixed in freshly prepared $4 \%$ buffered paraformaldehyde in phosphate-buffered saline (PBS) at $4{ }^{\circ} \mathrm{C}$ for over $40 \mathrm{~h}$. Then, the tissues were dehydrated in graded alcohol and embedded in paraffin (Leica, Wetzlar, Hessen, Germany). Sections of uteri were processed for immunohistochemical detection. Briefly, the sections $(5 \mu \mathrm{m})$ were deparaffinized and rehydrated in xylene and a graded series of ethyl alcohol, respectively, and then rinsed in PBS. Antigen retrieval was performed by placing the slides in boiling citric acid buffer $(10 \mathrm{mmol} / \mathrm{l}$ of citrate sodium and $10 \mathrm{mmol} / \mathrm{l}$ of citric acid) for $15 \mathrm{~min}$. The sections were cooled to room temperature and sequentially incubated at room temperature with $3 \%$ hydrogen peroxide $\left(\mathrm{H}_{2} \mathrm{O}_{2}\right)$ in methanol for $15 \mathrm{~min}$ to quench endogenous peroxidases. The sections were then incubated with a rabbit anti-NDRG2 primary antibody (Abcam, Cambridge, UK) overnight at $4{ }^{\circ} \mathrm{C}$. After being washed with PBS, the sections were incubated with a biotinconjugated donkey anti-rabbit secondary antibody (1:200 in blocking solution, Proteintech Company, Wuhan, China). After another wash in PBS, they were incubated with peroxidase-conjugated streptavidin (1:200 in blocking solution, Proteintech Company) for $2 \mathrm{~h}$. Then, they were stained with DAB (DAB, Zhongshan Corp., Beijing, China) according to the manufacturer's protocol and counterstained with hematoxylin (Sigma). For the negative controls, $10 \%$ donkey serum was used instead of primary antibody. All the sections were examined and photographed under a microscope (DFC420C, Leica).

For vimentin and cytokeratin detection, cultured ESCs were washed in PBS and fixed with PBS containing $4 \%$ paraformaldehyde for $20 \mathrm{~min}$. After being washed in PBS, the cells were incubated in blocking buffer $(0.2 \%$ Triton-X100 and $10 \%$ BSA in PBS) for $1 \mathrm{~h}$. Next, they were incubated with blocking buffer containing an antivimentin mouse monoclonal antibody (1:100 dilution, Cell Signaling, Beverly, MA), anti-cytokeratin 8 mouse monoclonal antibody (1:50 dilution, Cell Signaling), or negative control mouse IgG antibody at $4{ }^{\circ} \mathrm{C}$ overnight. After another wash in PBS, the cells were incubated in blocking buffer containing a biotin-conjugated donkey antirabbit antibody (1:200 in blocking solution, Proteintech Company) for $30 \mathrm{~min}$. Then, the cells were again washed in PBS and incubated with peroxidase-conjugated streptavidin (1:200 in blocking solution, Proteintech Company) for $2 \mathrm{~h}$. Next, the samples were stained with DAB (DAB, Zhongshan Corp.) according to the manufacturer's protocol. Finally, after being washed and stained with hematoxylin, the cells were observed and photographed under a microscope (DFC420C, Leica).

\section{Real-time PCR analysis}

Total RNA was extracted from uterine tissues or ESCs using TRIzol reagent (Invitrogen) according to the manufacturer's instructions. Extracted RNA was dissolved in diethylpyrocarbonate (DEPC, Sigma)-treated water, and the RNA concentration and purity were estimated by measuring absorbance at 260 and $280 \mathrm{~nm}$ with a NanoDrop 2000 (Thermo Scientific, Waltham, MA). cDNAs was synthesized using M-MLV reverse transcriptase (Promega, Madison, WI), according to the manufacturer's instructions. Real-time PCR was performed in a $20 \mu \mathrm{l}$ reaction volume using an ABI 7500 thermal cycler (Applied Biosystems, Foster City, CA). The thermal cycling conditions were $95{ }^{\circ} \mathrm{C}$ for $30 \mathrm{~s}$, followed by 40 cycles at $94{ }^{\circ} \mathrm{C}$ 
for $5 \mathrm{~s}$ and $60{ }^{\circ} \mathrm{C}$ for $30 \mathrm{~s}$. Melt curve analysis and agarose gel electrophoresis were then conducted to monitor the purity of the PCR products. Beta-actin was used as an endogenous control. The following primers were used: NDRG2, sense, 5'-AGAACTTCGTGCGGGTT CAT-3', antisense, 5' -TCGCGACAGAATGTAGGCTC-3'; decidual/trophoblast PRL-related protein (DTPRP), sense, 5' -AAGAATGCCCTTCAGCGAGC-3', antisense, 5' -AG CTGGTGGGTTTGTGACAT-3'; and beta-actin, sense, 5'-GGCTGTATTCCCCTCCATCG-3', antisense, 5'-CC AGTTGGTAACAATGCCATGT-3'.

\section{Western blotting}

The collected uterine tissues were quickly frozen in liquid nitrogen and granulated into a fine powder. The tissue powder was homogenized in lysis buffer (Beyotime, China). Then, the tissue lysate was centrifuged, and the supernatant was transferred into a new tube. Cultured ESCs were collected in lysis buffer, and the lysate was centrifuged to collect the supernatant. Protein concentrations were measured by Bradford assay (Bio-Rad, Hercules, $\mathrm{CA})$, and $50 \mu \mathrm{g}$ of total protein was separated on a $12 \%$ acrylamide gel and then transferred electrophoretically onto nitrocellulose membranes (Millipore). The membranes were incubated overnight at $4{ }^{\circ} \mathrm{C}$ with specific primary antibodies against NDRG2 and beta-actin (Santa Cruz), followed by incubation with the appropriate secondary antibodies. The blot was developed using a PhosphaGLO AP Substrate Kit (KPL, Gaithersburg, MD) according to the manufacturer's protocol. All samples were analyzed by Western blot in triplicate. Band intensities were quantified by densitometry using ImageJ software (U.S. National Institutes of Health, MD).

\section{Statistical analysis}

All values were presented as the mean \pm SEM, as determined from at least three independent experiments. Statistical significance was assessed by one-way ANOVA. A $P<0.05$ was considered statistically significant. Statistical analysis was conducted using SPSS 19.0 software (SPSS Software, Chicago, IL).

\section{Results}

\section{Uterine NDRG2 expression during the estrous cycle and} peri-implantation period

The uterine expression patterns of NDRG2 mRNA and NDRG2 protein during the mouse estrous cycle were determined by real-time PCR and IHC, respectively. The results showed distinctive NDRG2 protein signals in luminal and glandular epithelial cells at the diestrus (Fig. 1a), proestrus (Fig. 1b), estrous (Fig. 1c) and metestrus phases (Fig. 1d), with the most prominent expression detected during the estrous phase, along with weak positive signals in stromal cells (Fig.1c). Consistently, real-time PCR analysis revealed that NDRG2 mRNA expression was significantly increased during the estrous phase compared with that during the diestrus, proestrus and metestrus phases (Fig. 1e).

Prior to the initiation of implantation, uterine NDRG2 mRNA expression gradually increased from day 1 (D1) to day 4 (D4) of pregnancy. During implantation (day 5 to day 8 of pregnancy), NDRG2 mRNA expression was differentially regulated between the implantation sites and non-implantation sites. Its expression was significantly up-regulated at the implantation sites, whereas it was obviously down-regulated at the non-implantation sites (Fig. 2a). Meanwhile, the results of Western blot analysis showed that uterine NDRG2 protein expression was significantly increased after the initiation of implantation (day 5 of pregnancy), and its expression at the implantation sites was remarkably higher than that at the non-implantation sites (Fig. 2b). Furthermore, the spatiotemporal expression of NDRG2 protein in the mouse uterus during early pregnancy was examined by IHC. There was no detectable NDRG2 protein signal in the uterine tissue obtained from pregnant mice on day 1 (Fig. 2c/b) or day 3 (Fig. 2c/c). On day 4 of pregnancy, faint NDRG2 protein signals were noted in the subepithelial stromal bed (Fig. 2c/d). On day 5 of pregnancy, the distinct accumulation of NDRG2 protein signals was observed in both the secondary decidual zone and the embryo, with faint expression in the primary decidua immediately adjacent to the implanting embryo (Fig. 2c/e, f). The distribution of NDRG2 protein signals on day 8 of pregnancy was similar to that on day 5 , except that the positive signals also accumulated in trophoblasts at implantation sites (Fig. 2c/g, h).

\section{The effects of steroid hormones on NDRG2 expression in the uterus}

Ovariectomized mice were used to examine the effects of steroid hormones on NDRG2 expression in the uterus. Compared with the control (Fig. 3a), treatment with $E_{2}$ (Fig. 3b) or $\mathrm{P}_{4}$ (Fig. 3c) significantly induced NDRG2 protein expression in both the luminal and glandular epithelia, and the combined administration of $\mathrm{E}_{2}$ and $\mathrm{P}_{4}$ resulted in a similar effect on its expression (Fig. 3d). A similar alteration in NDRG2 mRNA expression was observed following treatment with $\mathrm{E}_{2}$ or $\mathrm{P}_{4}$ (Fig. 3e).

The association of uterine NDRG2 expression and artificial decidualization and activated implantation

The artificial decidualization model was used to examine whether uterine NDRG2 expression is dependent on the presence of a living embryo or whether it is induced by the decidualization reaction alone. The results of IHC analysis showed strong NDRG2 protein signals in decidualized stromal cells (Fig. 4b), whereas no visible signals were found in control uteri (Fig. 4a). Meanwhile, uterine 

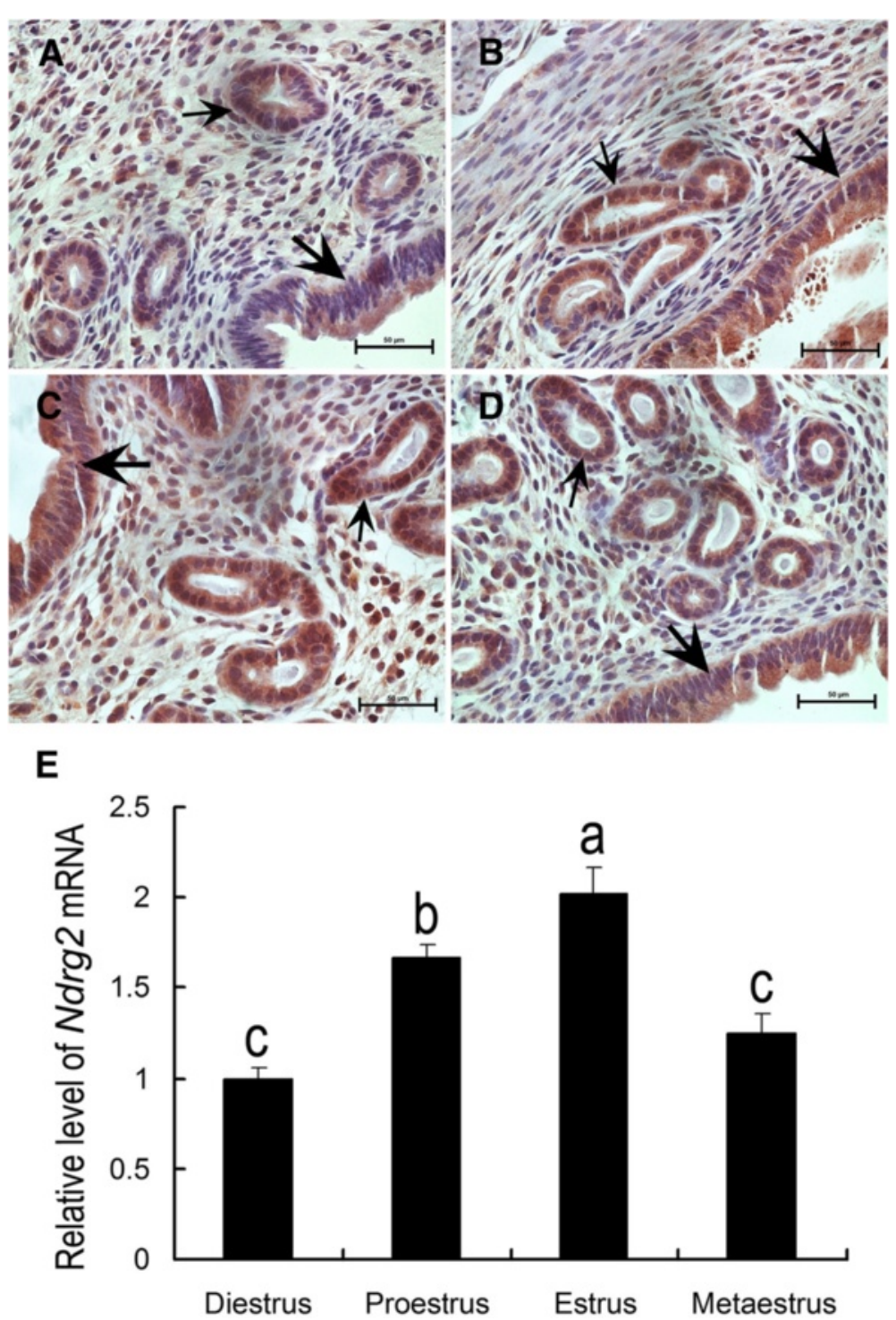

Fig. 1 NDRG2 expression in the mouse uterus during the estrous cycle. Upper: immunohistochemical analysis of NDRG2 expression during the diestrus (a), proestrus (b), estrous (c) and metestrus (d) phases in the mouse uterus. Below: quantitative PCR analysis of NDRG2 mRNA expression (e) in the uterus during the estrous cycle $(n=3)$. The thick arrow shows the luminal epithelium. The small arrow indicates the glandular epithelium. The columns with different superscripts are significantly different $(P<0.05)$

NDRG2 mRNA expression was also found to be significantly up-regulated by artificial decidualization (Fig. 4c). In the delayed implantation model, the NDRG2 protein was abundantly expressed in activated implantation uteri (Fig. 4e), and it was weakly expressed in delayed implantation uteri (Fig. 4d). Likewise, significantly higher NDRG2 mRNA levels were detected in the activated implantation uteri compared with those in the delayed uteri (Fig. 4f).

\section{NDRG2 expression in cultured ESCs during the process of} in vitro decidualization

To explore the function of NDRG2 in the decidualization of mouse ESCs, a mouse primary ESCs culture system was established. Positive staining for vimentin and negative staining for cytokeratin were considered to be indicative of ESC purity (Fig. 5a). The transformation of decidual cells from ESCs was indicated by DTPRP mRNA expression [26] (Fig. 5b). The mRNA and protein levels of NDRG2 were found to be significantly increased during in vitro decidualization (Fig. 5c, d).

\section{The effects of decreased NDRG2 expression in ESCs on} in vitro decidualization

To further explore the role of NDRG2 in the decidualization of ESCs, NDRG2 expression was knocked down in cultured ESCs using targeting siRNAs. As a result, its 

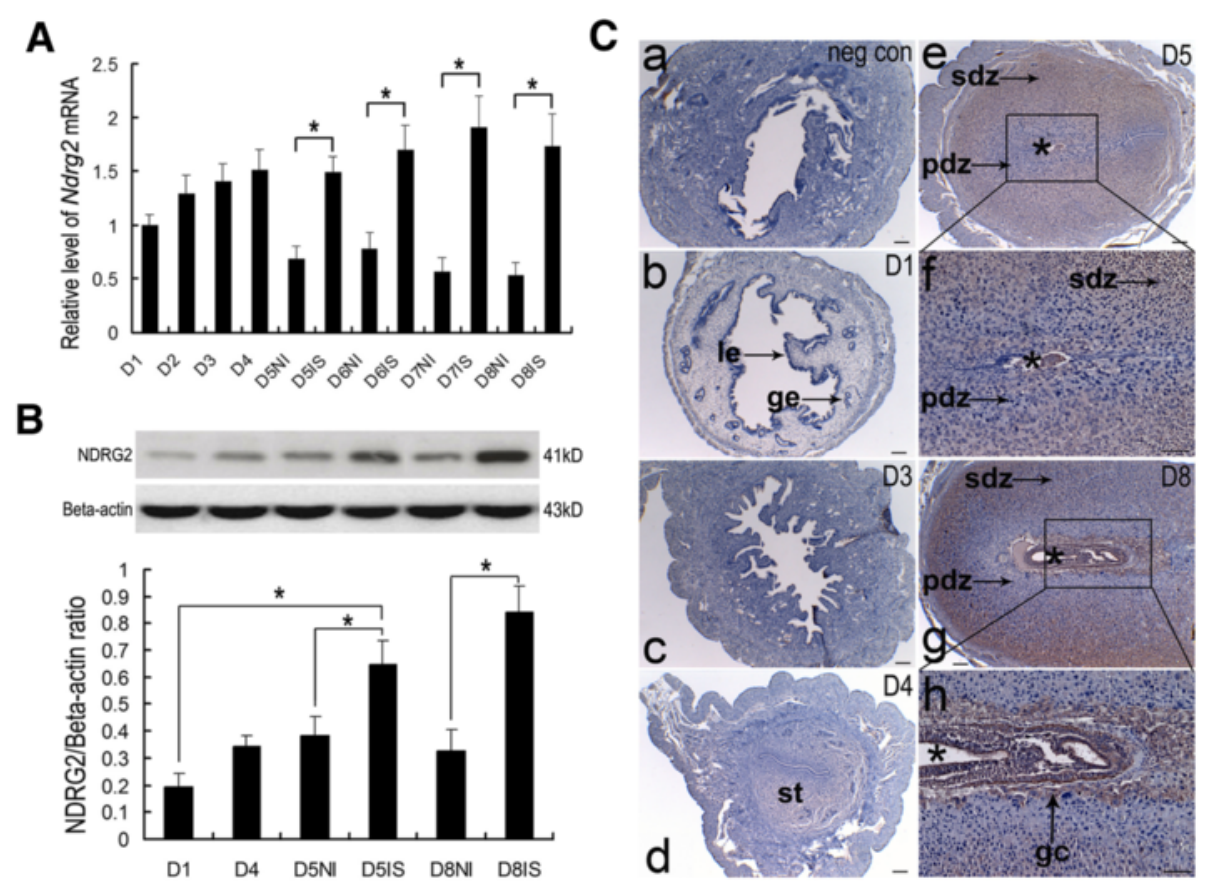

Fig. 2 NDRG2 expression in the mouse uterus during early pregnancy. a Quantitative PCR analysis of NDRG2 mRNA expression in the uterus during early pregnancy $\left(n=3,{ }^{*} P<0.05\right)$. b Western blot and densitometric analyses of uterine NDRG2 protein levels during early pregnancy $(n=3)$. All experiments were repeated three times. The data are shown as the mean \pm SEM. ${ }^{*} P<0.05$. c Immunohistochemical analysis of uterine NDRG2 protein expression on days 1, 3, 4, 5, and 8 of pregnancy. IS, implantation sites; NI, non-implantation sites. ${ }^{*}$, indicates the location of the embryo. le, luminal epithelium; ge, glandular epithelium; st, stroma; pdz, primary decidual zone; sdz, secondary decidual zone; D, day of pregnancy; gc, giant cell; Scale bar represents $100 \mu \mathrm{m}$

expression was reduced by more than $60 \%$ in NDRG2 siRNA-transfected ESCs compared with that in control ESCs (Fig. 6a, c, d), and this reduction was correlated with a significant decrease in DTPRP mRNA expression (Fig. 6b), indicating that down-regulation of NDRG2 expression inhibited the decidualization of mouse ESCs.

\section{Discussion}

The present study demonstrated the expression pattern of NDRG2 in the uterus during the estrous cycle and early pregnancy in mice. Uterine NDRG2 expression was found to peak during the estrous phase and to be induced by the ovarian steroid hormones $E_{2}$ and $P_{4}$. During early pregnancy, uterine NDRG2 expression was significantly increased at implantation sites, with predominant localization in the decidual zone. This increase in expression was accompanied by the activation of delayed implantation, as well as artificially induced decidualization, both in vivo and in vitro. Furthermore, down-regulation of NDRG2 expression in mouse ESCs significantly inhibited decidualization in vitro.

The synergistic actions of $\mathrm{E}_{2}$ and $\mathrm{P}_{4}$ are critical for regulation of the estrous cycle and establishment of uterine receptivity [27, 28]. A putative estrogen-response element (ERE) is located in the promoter region of the NDRG2 gene, and NDRG2 expression in astrocytes is regulated by estrogen $[29,30]$. In the present study, we found that both $\mathrm{E}_{2}$ and $\mathrm{P}_{4}$ had stimulatory effects on uterine NDRG2 expression in ovariectomized mice (Fig. 3). In addition, during the normal estrous cycle, uterine NDRG2 expression was significantly increased during the proestrus and estrous phases, whereas it was decreased during the metestrus and diestrus phases (Fig. 1), consistent with the $\mathrm{E}_{2}$ surge that takes place during the proestrus and estrous phases [31]. Because NDRG2 expression was detected in luminal and glandular epithelial cells as well as in stromal cells, we speculated that it might participate in regulating cyclic proliferation and differentiation in endometrial epithelial/stromal cells to optimally prepare for embryo implantation under the control of $\mathrm{E}_{2}$ and $\mathrm{P}_{4}$ during the estrous cycle.

Successful embryo implantation is integral to the establishment of pregnancy, and initiation of implantation coincides with the establishment of uterine receptivity and the subsequent decidualization of endometrial stromal cells (ESCs) [32]. In the mouse, a pre-ovulatory $\mathrm{E}_{2}$ surge stimulates uterine epithelial cell proliferation on day 1 of pregnancy, followed by a rise in the $\mathrm{P}_{4}$ level and its secretion by the newly formed corpora lutea, which initiates uterine stromal cell proliferation on day 3. Embryos enter the uterus at midnight on day 3 or in the early hours of day 4 after the uterus is exposed to an 


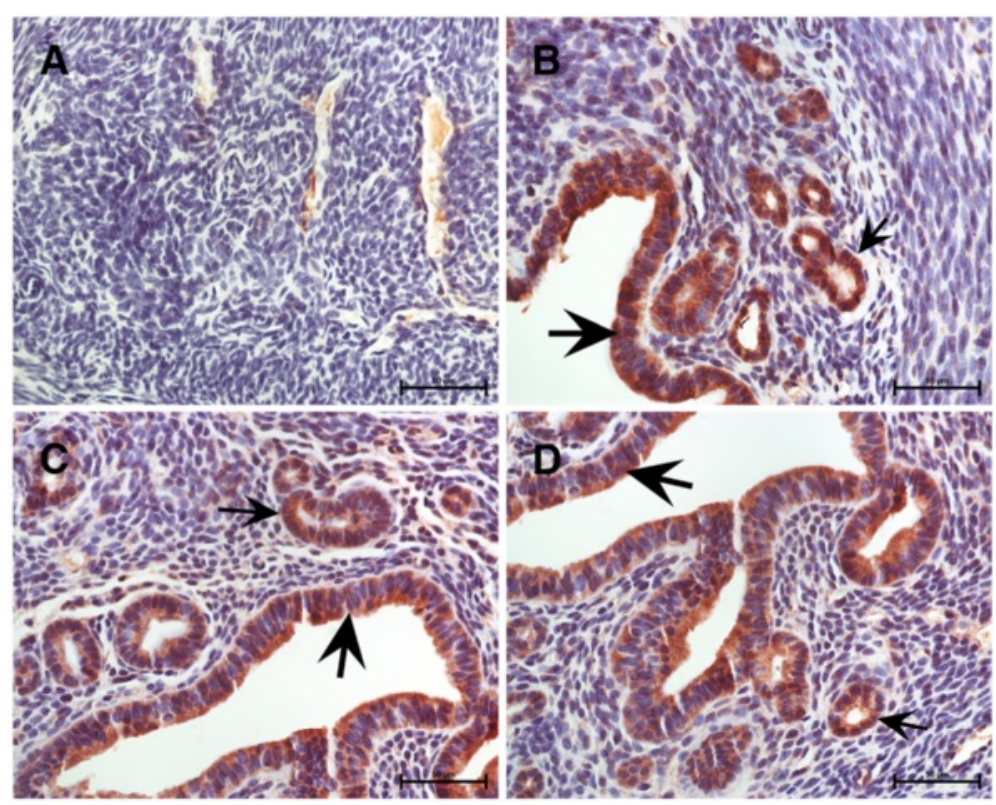

E

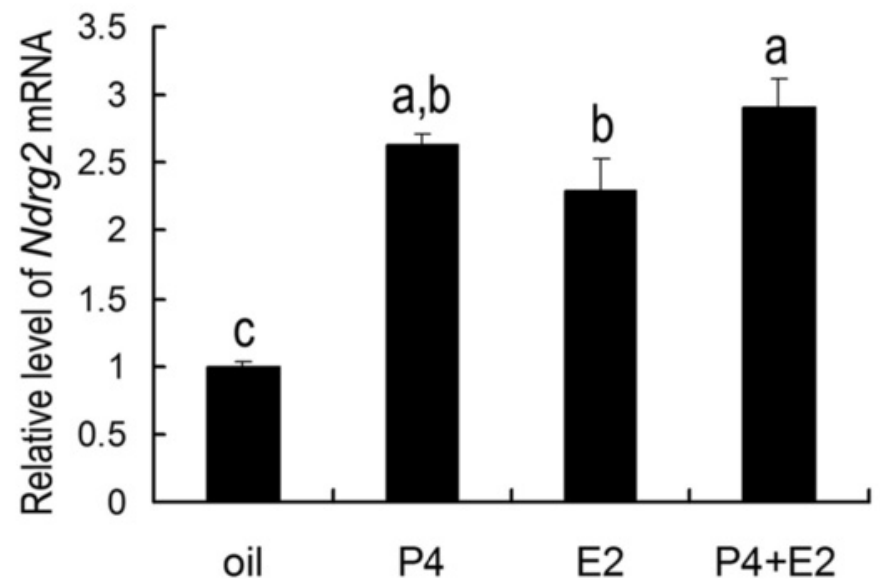

Fig. 3 The effects of steroid hormones on NDRG2 expression in the uterus. Upper: immunohistochemical analysis of NDRG2 protein expression in the uteri of ovariectomized mice after oil (a), progesterone (b), estrogen (c), and progesterone plus estrogen treatments (d). Below: quantitative PCR analysis of NDRG2 mRNA expression (e) in the uterus following steroid hormone treatment $(n=3)$. The thick arrow indicates the luminal epithelium. The small arrow shows the glandular epithelium. The columns with different superscripts are significantly different $(P<0.05)$

increased concentration of $\mathrm{P}_{4}$ for at least $24 \mathrm{~h}$ on day 3 followed by exposure to estrogen, causing it to be receptive for embryo implantation [33]. We found that uterine NDRG2 expression remained increased during the preimplantation period from day 1 to day 4, suggesting its potential role in establishing uterine receptivity under the regulation of ovarian steroids.

Once mouse embryos attach to a receptive endometrium, decidualization is triggered by extensive proliferation and differentiation of ESCs into decidual stromal cells (DSCs) at embryo implantation sites. Because the decidual response can be induced in a reproducible manner in the absence of an embryo and decidual zones are easily discernable, the mouse is a good model to investigate the mechanism of decidualization. In the mouse, at least three factors may be necessary for normal decidualization, including $\mathrm{E}_{2}, \mathrm{P}_{4}$ and embryonic or physical stimulation (by intra-luminal infusion of oil or scratching with a needle). Increases in $\mathrm{E}_{2}$ and $\mathrm{P}_{4}$ stimulate the proliferation and differentiation of ESCs surrounding invading trophoblast cells to support the decidualization process [33-35]. In the present study, a significant increase in NDRG2 expression was observed at implantation sites on days 5 and 8 of pregnancy in the mice, and NDRG2 protein signals were predominantly localized to the decidual zone. Moreover, because $\mathrm{E}_{2}$ and $\mathrm{P}_{4}$ induced NDRG2 expression in the uterus and increased its expression in ESCs following artificial decidualization 

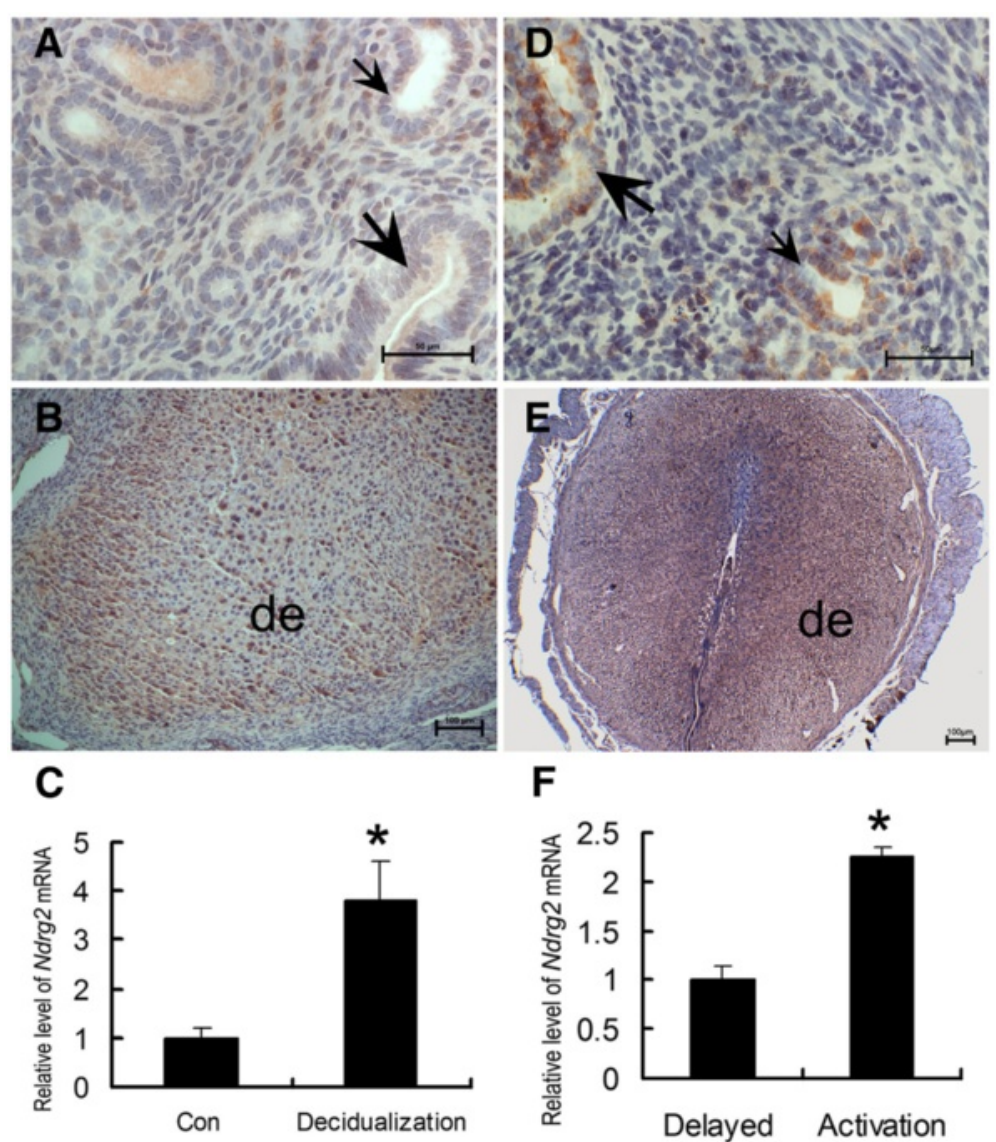

Fig. 4 Uterine NDRG2 expression following artificial decidualization and activation of delayed implantation. Immunohistochemical analysis of uterine NDRG2 protein expression following artificial decidualization (b) and in its contralateral uninjected uterine horn (a), under delayed implantation (d) and activation (e). Quantitative PCR analysis of NDRG2 mRNA expression in the uterus following artificial decidualization (c) and activation of delayed implantation $(\mathbf{f})(n=3)$. The thick arrow indicates the luminal epithelium. The small arrow shows the glandular epithelium. De, decidua; *, significantly different from control $(P<0.05)$

(Fig. 4 and Fig. 5), we hypothesized that it might be involved in the decidualization of these cells. To further investigate this hypothesis, we specifically knocked down NDRG2 expression in mouse ESCs using NDRG2targeting siRNAs and subsequently evaluated the effect of decreased NDRG2 expression on ESC decidualization in vitro using DTPRP as a marker of decidualization. Decreased expression of this gene was found to remarkably inhibit decidualization in vitro (Fig. 6), indicating that it may participate in this process.

An implantation site is distinguished from a nonimplantation site not only by the presence of DSCs and trophoblast cells but also by the enrichment of decidual immune cells. Dendritic cells (DCs) are the most predominant immune cells in decidua at implantation sites, and they play a critical role in preserving a hospitable microenvironment for pregnancy [36]. Although NDRG2 expression in decidual DCs has not been reported, its expression in DCs derived from $\mathrm{CD}^{34+}$ progenitor cells has been detected. Inhibition of DCs differentiation is accompanied by reduced NDRG2 expression, and the down-regulation of its expression negatively affects the ability of DCs to stimulate T cells proliferation [37]. Thus, an increased in NDRG2 expression at implantation sites during early pregnancy might also be associated with the differentiation and maturation of decidual DCs. NDRG2 expression in decidual DCs will be explored further by our group.

Although the exact role of NDRG2 in regulating ESCs and DSCs needs to be further explored, NDRG2 has been reported to contain several potential phosphorylation sites and to be phosphorylated by Akt [13] and SGK1 [14]. Importantly, a decrease in uterine Akt expression has been shown to result in abnormal decidualization in mice [38], and reduced SGK1 expression in DSCs has been observed in recurrent spontaneous miscarriage (RSM) patients [39]. Thus, it is reasonable to believe that the function of NDRG2 in ESCs and DSCs might be partially regulated by the Akt or/and SGK1 signaling pathway(s). Conversely, the appropriate 

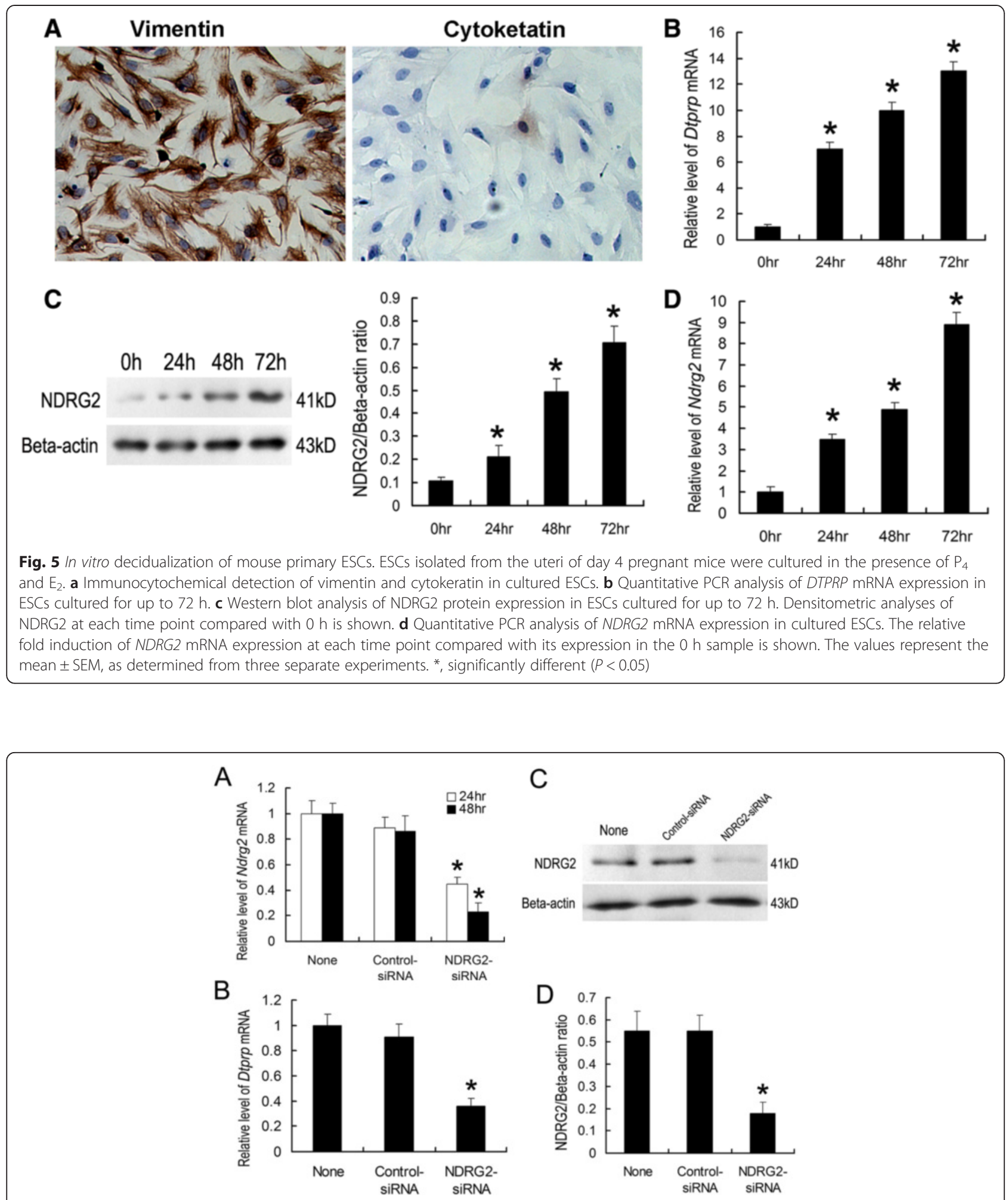

Fig. 6 Down-regulation of NDRG2 expression in ESCs inhibits in vitro decidualization. Cultured mouse ESCs were transfected with NDRG2-targeting siRNAs (100 nM) (a non-targeting siRNA was used as a control) at the time of plating. Quantitative PCR analyses of NDRG2 mRNA expression (a) and DTPRP mRNA expression (b) in ESCs transfected with NDRG2-targeting siRNAs or non-targeting siRNAs at $24 \mathrm{~h}$ and $48 \mathrm{~h}$. Western blot (c) and densitometric analyses (d) of NDRG2 protein levels in ESCs at $72 \mathrm{~h}$ after transfection. The relative fold induction of NDRG2 protein expression compared with its expression in non-siRNA-treated group is shown. The values represent the mean $\pm \mathrm{SEM}$, as determined from three separate experiments. *, significantly different $(P<0.05)$ 
invasion of trophoblast cells into maternal stroma is also a pivotal event that occurs during implantation [40]. Because we observed NDRG2 protein expression in trophoblast cells at implantation sites on day 8 of pregnancy in the mice in this study (Fig. 2) and it has been demonstrated that $\mathrm{E}_{2}$ and $\mathrm{P}_{4}$ participate in the regulation of trophoblast cells $[41,42]$, we hypothesize that NDRG2 might also be involved in the invasion of trophoblast cells during early pregnancy.

\section{Conclusions}

In summary, the present study has demonstrated that steroid hormones stimulate NDRG2 expression in the uterus and that NDRG2 expression is significantly upregulated at implantation sites during early pregnancy in mice. During in vivo and in vitro artificial decidualization, NDRG2 expression was found to be remarkably increased. Further, down-regulation of its expression in ESCs inhibited in vitro decidualization. These results suggest that NDRG2 might be essential for embryo implantation and decidualization.

\begin{abstract}
Abbreviations
DCs: Dendritic cells; DEPC: Diethylpyrocarbonate; DRPRP: Decidual/trophoblast PRL-related protein; DSCs: Decidual stromal cells; ESCs: Endometrial stromal cells; ERE: Estrogen response element; $E_{2}$ : 17ß-estradiol; FBS: Fetal calf serum; HBSS: Hanks' balanced salt solution; $\mathrm{H}_{2} \mathrm{O}_{2}$ : Hydrogen peroxide; IHC: Immunohistochemistry; NDRG2: N-myc down-regulated gene 2; PBS: Phosphate-buffered saline; PE: Preeclampsia; PKB: Protein kinase B; $P_{4}$ : Progesterone; RSM: Recurrent spontaneous miscarriage; siRNA: small interfering RNA; SGK1: Glucocorticoid-induced kinase 1.
\end{abstract}

\section{Competing interests}

The authors declare that they have no competing interests.

\section{Authors' contributions}

YG performed immunohistochemistry and PCR analyses. QY managed the animals, collected the tissue samples, and performed Western blot analysis of NDRG2. JMW participated in the collection of tissue samples. YPH performed the cell culture experiment. ZGS provided assistance for the immunohistochemistry and Western blotting procedures. HQZ participated in the drafting of the manuscript. XZ and JW contributed to the conception, design, acquisition and interpretation of data, and drafting of the manuscript. All the authors read and approved the final manuscript.

\section{Acknowledgements}

This study was funded by the Shanghai Municipal Science \& Technology Committee (No. 12JC1407601, GY, WJM, HYP, SZG, WJ), the National Natural Science Foundation of China (No. 31301222, ZX, YQ, ZHQ), and the Shanghai Municipal Commission of Health and Family Planning Project of Science and Technology Development Fund (No. 2013JG03, ZX, SZG). The authors are grateful to American Journal Experts for careful editing of the manuscript.

\author{
Author details \\ 'Shanghai Medical School, Fudan University, Shanghai, China. ${ }^{2}$ NPFPC Key \\ Laboratory of Contraceptive Drugs \& Devices, Shanghai Institute of Planned \\ Parenthood Research, Shanghai, China. ${ }^{3}$ The Second Hospital of Tianjin \\ Medical University, Tianjin, China.
}

Received: 6 February 2015 Accepted: 20 May 2015

Published online: 27 May 2015

\section{References}

1. Aplin JD. Embryo implantation: the molecular mechanism remains elusive. Reprod Biomed Online. 2006;13(6):833-9.
2. Harun R, Ruban L, Matin M, Draper J, Jenkins NM, Liew GC, et al. Cytotrophoblast stem cell lines derived from human embryonic stem cells and their capacity to mimic invasive implantation events. Hum Reprod. 2006;21(6):1349-58. doi:10.1093/humrep/del017.

3. Ferretti C, Bruni L, Dangles-Marie V, Pecking AP, Bellet D. Molecular circuits shared by placental and cancer cells, and their implications in the proliferative, invasive and migratory capacities of trophoblasts. Hum Reprod Update. 2007;13(2):121-41. doi:10.1093/humupd/dml048.

4. Cameo P, Srisuparp S, Strakova Z, Fazleabas AT. Chorionic gonadotropin and uterine dialogue in the primate. Reprod Biol Endocrinol. 2004;2:50. doi:10.1186/1477-7827-2-50.

5. Loke YW, King A, Burrows TD. Decidua in human implantation. Hum Reprod. 1995;10 Suppl 2:14-21.

6. Gellersen B, Brosens IA, Brosens JJ. Decidualization of the human endometrium: mechanisms, functions, and clinical perspectives. Semin Reprod Med. 2007;25(6):445-53. doi:10.1055/s-2007-991042.

7. Ma M, Zhao K, Wu W, Sun R, Fei J. Dynamic expression of N-myc in mouse embryonic development using an enhanced green fluorescent protein reporter gene in the N-myc locus. Dev Growth Differ. 2014;56(2):152-60. doi:10.1111/dgd.12115.

8. Yao L, Zhang J, Liu X. NDRG2: a Myc-repressed gene involved in cancer and cell stress. Acta Biochim Biophys Sin. 2008;40(7):625-35.

9. Liu N, Wang L, Liu X, Yang Q, Zhang J, Zhang W, et al. Promoter methylation, mutation, and genomic deletion are involved in the decreased NDRG2 expression levels in several cancer cell lines. Biochem Biophys Res Commun. 2007;358(1):164-9. doi:10.1016/j.bbrc.2007.04.089.

10. Hu XL, Liu XP, Lin SX, Deng YC, Liu N, Li X, et al. NDRG2 expression and mutation in human liver and pancreatic cancers. World J Gastroenterol. 2004;10(23):3518-21.

11. Assamaki R, Sarlomo-Rikala M, Lopez-Guerrero JA, Lasota J, Andersson LC, Llombart-Bosch A, et al. Array comparative genomic hybridization analysis of chromosomal imbalances and their target genes in gastrointestinal stromal tumors. Gene Chromosome Canc. 2007;46(6):564-76. doi:10.1002/gcc.20439.

12. Hu XL, Liu XP, Deng YC, Lin SX, Wu L, Zhang J, et al. Expression analysis of the NDRG2 gene in mouse embryonic and adult tissues. Cell Tissue Res. 2006:325(1):67-76. doi:10.1007/s00441-005-0137-5.

13. Burchfield JG, Lennard AJ, Narasimhan S, Hughes WE, Wasinger VC, Corthals GL, et al. Akt mediates insulin-stimulated phosphorylation of Ndrg2: evidence for cross-talk with protein kinase C theta. J Biol Chem. 2004;279(18):18623-32. doi:10.1074/jbc.M401504200.

14. Murray JT, Campbell DG, Morrice N, Auld GC, Shpiro N, Marquez R, et al. Exploitation of KESTREL to identify NDRG family members as physiological substrates for SGK1 and GSK3. Biochem J. 2004;384(Pt 3):477-88. doi:10.1042/BJ20041057.

15. Lyu SY, Choi JH, Lee HJ, Park WB, Kim GJ. Korean mistletoe lectin promotes proliferation and invasion of trophoblast cells through regulation of Akt signaling. Reprod Toxicol. 2013;39:33-9. doi:10.1016/j.reprotox.2013.03.011.

16. Gouon-Evans V, Pollard JW. Eotaxin is required for eosinophil homing into the stroma of the pubertal and cycling uterus. Endocrinology. 2001;142(10):4515-21. doi:10.1210/endo.142.10.8459.

17. O'Sullivan CM, Liu SY, Rancourt SL, Rancourt DE. Regulation of the strypsinrelated proteinase ISP2 by progesterone in endometrial gland epithelium during implantation in mice. Reproduction. 2001;122(2):235-44.

18. Hayashi K, Erikson DW, Tilford SA, Bany BM, Maclean 2nd JA, Rucker 3rd EB, et al. Wnt genes in the mouse uterus: potential regulation of implantation. Biol Reprod. 2009;80(5):989-1000. doi:10.1095/biolreprod.108.075416.

19. Chen Y, Ni H, Ma XH, Hu SJ, Luan LM, Ren G, et al. Global analysis of differential luminal epithelial gene expression at mouse implantation sites. J Mol Endocrinol. 2006;37(1):147-61. doi:10.1677/jme.1.02009.

20. Maurya VK, Jha RK, Kumar V, Joshi A, Chadchan S, Mohan JJ, et al. Transforming growth factor-beta 1 (TGF-B1) liberation from its latent complex during embryo implantation and its regulation by estradiol in mouse. Biol Reprod. 2013;89(4):84. doi:10.1095/biolreprod.112.106542.

21. Hu SJ, Ren G, Liu JL, Zhao ZA, Yu YS, Su RW, et al. MicroRNA expression and regulation in mouse uterus during embryo implantation. J Biol Chem. 2008;283(34):23473-84. doi:10.1074/jbc.M800406200.

22. Nautiyal J, Kumar PG, Laloraya M. 17Beta-estradiol induces nuclear translocation of CrkL at the window of embryo implantation. Biochem Biophys Res Commun. 2004;318(1):103-12. doi:10.1016/j.bbrc.2004.04.005.

23. Hamatani T, Daikoku T, Wang H, Matsumoto H, Carter MG, Ko MS, et al. Global gene expression analysis identifies molecular pathways 
distinguishing blastocyst dormancy and activation. Proc Natl Acad Sci U S A 2004;101(28):10326-31. doi:10.1073/pnas.0402597101.

24. Smith SE, French MM, Julian J, Paria BC, Dey SK, Carson DD. Expression of heparan sulfate proteoglycan (perlecan) in the mouse blastocyst is regulated during normal and delayed implantation. Dev Biol. 1997;184(1):38-47. doi:10.1006/dbio.1997.8521.

25. Li Q, Kannan A, Wang W, Demayo FJ, Taylor RN, Bagchi MK, et al. Bone morphogenetic protein 2 functions via a conserved signaling pathway involving Wnt4 to regulate uterine decidualization in the mouse and the human. J Biol Chem. 2007;282(43):31725-32. doi:10.1074/jbc.M704723200.

26. Kimura F, Takakura K, Takebayashi K, Ishikawa H, Kasahara K, Goto S, et al. Messenger ribonucleic acid for the mouse decidual prolactin is present and induced during in vitro decidualization of endometrial stromal cells. Gynecol Endocrinol. 2001;15(6):426-32

27. Singh $M$, Chaudhry $P$, Asselin E. Bridging endometrial receptivity and implantation: network of hormones, cytokines, and growth factors. J Endocrinol. 2011;210(1):5-14. doi:10.1530/JOE-10-0461.

28. Salgado RM, Favaro RR, Zorn TM. Modulation of small leucine-rich proteoglycans (SLRPs) expression in the mouse uterus by estradiol and progesterone. Reprod Biol Endocrinol. 2011;9:22. doi:10.1186/1477-7827-9-22

29. Li Y, Yang J, Li S, Zhang J, Zheng J, Hou W, et al. N-myc downstreamregulated gene 2, a novel estrogen-targeted gene, is involved in the regulation of Na+/K + -ATPase. J Biol Chem. 2011;286(37):32289-99. doi:10.1074/jbc.M111.247825.

30. Ma YL, Qin P, Feng DY, Li Y, Zhang LX, Liu ZY, et al. Estrogen regulates the expression of Ndrg2 in astrocytes. Brain research. 2014;1569:1-8. doi:10.1016/j.brainres.2014.04.036

31. Horvat B. Cyclic changes in the expression of endometrial proteins of the mouse during the normal estrus cycle. In vivo. 1991;5(4):345-7.

32. Das SK. Cell cycle regulatory control for uterine stromal cell decidualization in implantation. Reproduction. 2009:137(6):889-99. doi:10.1530/REP-08-0539.

33. Paulson RJ. Hormonal induction of endometrial receptivity. Fertil Steril. 2011:96(3):530-5. doi:10.1016/j.fertnstert.2011.07.1097.

34. King $A E$, Critchley $\mathrm{HO}$. Oestrogen and progesterone regulation of inflammatory processes in the human endometrium. J Steroid Biochem Mol Biol. 2010;120(2-3):116-26. doi:10.1016/j.jsbmb.2010.01.003.

35. Ramathal CY, Bagchi IC, Taylor RN, Bagchi MK. Endometrial decidualization: of mice and men. Semin Reprod Med. 2010;28(1):17-26. doi:10.1055/s-0029-1242989.

36. Erlebacher A. Immunology of the maternal-fetal interface. Annu Rev Immunol. 2013;31:387-411. doi:10.1146/annurev-immunol-032712-100003.

37. Choi SC, Kim KD, Kim JT, Kim JW, Lee HG, Kim JM, et al. Expression of human NDRG2 by myeloid dendritic cells inhibits down-regulation of activated leukocyte cell adhesion molecule (ALCAM) and contributes to maintenance of T cell stimulatory activity. J Leukoc Biol. 2008;83(1):89-98 doi:10.1189/jlb.0507300.

38. Mori M, Kitazume M, Ose R, Kurokawa J, Koga K, Osuga Y, et al. Death effector domain-containing protein (DEDD) is required for uterine decidualization during early pregnancy in mice. J Clin Invest. 2011;121(1):318-27. doi:10.1172/JCl44723.

39. Salker MS, Christian M, Steel JH, Nautiyal J, Lavery S, Trew G, et al. Deregulation of the serum- and glucocorticoid-inducible kinase SGK1 in the endometrium causes reproductive failure. Nature medicine. 2011:17(11):1509-13. doi:10.1038/nm.2498.

40. Oreshkova T, Dimitrov R, Mourdjeva M. A cross-talk of decidual stromal cells, trophoblast, and immune cells: a prerequisite for the success of pregnancy. Am J Reprod Immunol. 2012;68(5):366-73. doi:10.1111/j.1600-0897.2012.01165.x.

41. Basak S, Dhar R, Das C. Steroids modulate the expression of alpha4 integrin in mouse blastocysts and uterus during implantation. Biol Reprod. 2002;66(6):1784-9.

42. Wang H, Bocca S, Anderson S, Yu L, Rhavi BS, Horcajadas J, et al. Sex steroids regulate epithelial-stromal cell cross talk and trophoblast attachment invasion in a three-dimensional human endometrial culture system. Tissue Eng Part C Methods. 2013:19(9):676-87. doi:10.1089/ten TEC.2012.0616.

\section{Submit your next manuscript to BioMed Central and take full advantage of:}

- Convenient online submission

- Thorough peer review

- No space constraints or color figure charges

- Immediate publication on acceptance

- Inclusion in PubMed, CAS, Scopus and Google Scholar

- Research which is freely available for redistribution

Submit your manuscript at www.biomedcentral.com/submit 